\title{
More Ways to Recombine Wood Fibers than You Can Shake a Stick At
}

Wood has been categorized as a renewable resource. In the industrial era, however, a dwindling supply of wood spurred the invention of techniques developed over the last 150 years that exploit a greater proportion of available wood. Their general principles involve the use of thin sheets or strips of wood assembled into final form with the use of adhesives.

Lumber cut from round logs produces waste. Eliminating this waste is one motivation for plywood since very little waste is produced when a log is rolled against a blade, creating sheets of wood veneer. These veneer layers, or plies, are laminated with adhesive and pressed together. When the direction of the grain of each lamination is alternated, the resulting boards possess a high degree of tensile strength. Adhesives contribute to plywood's strength by providing the bond between each ply. Early adhesives included animal hide glue and cassava-based vegetable glues, which were water soluble. Identifying waterproof adhesives became key to making plywood widely marketable.

John K. Mayo obtained a U.S. patent for plywood in 1865, but the technology did not become known at the time and the patent lapsed. Plywood reappeared in 1905 as a local product displayed at the Lewis and Clark Centennial Exposition in Portland, Oregon. This time, a market developed and plywood began to be used for cabinetry, doors, and car running boards. Although milk-based casein glues were introduced around 1900 and were more water-resistant than earlier adhesives, plywood's primary drawback remained its inability to perform in moist conditions because the adhesives would break down and the plies would delaminate.

Plywood is used most effectively in the form of wide, flat sheets, but there are other laminated wood products used as structural beams and columns. Traditionally, structural members are wood pieces cut straight from the tree, but the large assemblies required to span distances upward of 30 feet become prohibitively heavy. In 1901, Otto Hetzer of Weimar, Germany obtained a patent for a straight beam created from laminations of wood boards bonded, as was plywood, with casein adhesive under pressure. The laminations in this beam ran parallel to one another, mimicking the fibrous structure of a tree. Building up beams from laminations of smaller wood components allowed trees of average size and quality to be used, and reduced waste. Using small pieces of wood permitted the moisture content of the completed beam to be better controlled.

Hetzer patented a curved beam in 1906 . The curve allowed the beam to behave as an arch. Because this configuration capitalized on wood's natural fiber strength and the manufacturing process permitted defects to be removed, curved laminated beams could span longer distances than lumber beams. Wood now could be used to make beams that spanned as far as steel beams, which were more expensive.

The world wars and attendant government-sponsored research helped advance the technology and acceptance of engineered wood. During World War I, the U.S. Agriculture Department's Forest Products Laboratory conducted research into plywood suitable for airplane construction. As a result, casein-laminated plywood was used in airplane manufacture.

In 1920, the Forest Products Laboratory made an abortive foray into research on glued laminated timber structural members as they were being used in Switzerland. Interest in the technique revived in 1934, and the U.S. government, through the Works Projects Administration and the military, provided the first large-scale market for these products in the country. During World War II, plywood and glued laminated timber were being used instead of steel to construct factories, hangars, and warehouses for the war effort. Wood also continued to be used to build airplanes, including the Mosquito bomber.

The U.S. Navy sponsored research into waterproof synthetic adhesives to join timbers and to bond wood plies for ship construction; the results included PT boats. Phenol-formaldehyde resins had emerged in the early 1930 s as the first reliably water-resistant adhesives. Although adhesives containing formaldehyde-based resins had been known since the late 19th century, it was over 30 years before they entered commercial use. These adhesives are used in liquid form (or as a powder that must be mixed with water) and react under heat and pressure with an alkalai catalyst to form a resin with a high bond strength. Rather than simply bonding the wood plies to one another, these adhesives form three-dimensional networks of molecules, adding their structural strength to that of the wood. Following the war, the new polymer-based synthetic adhesives provided commercial laminated-glued lumber products with the long-sought water resistance.

One of the most recent developments in glued wood technology is oriented strand board (OSB), which combines principles of both plywood and glued laminated timber. Wood flakes a few inches long are bonded in layers whose fibers are arranged longitudinally for the board's outer surfaces and in a random overlapping crossed pattern in the center of the board. The adhesive used to bond the inner layer of strands is an isocyanate, which reacts chemically with the wood fibers to produce a very strong bond. OSB is used as a sheathing material, or skin, much like plywood, and also as the web component of wood beams with an Ishaped cross section.

Petroleum, which is commonly used to produce formaldehyde-based adhesives, has increased in price to the point that the search is on for other adhesive ingredients. Ironically, one of the most promising sources of an alternative is tannin, which occurs naturally in tree bark. Tanninformaldehyde resins presented potential in the $1960 \mathrm{~s}$, but have been developed commercially only in the last 10 years. Production of these resins for commercial use is being pursued in South Africa and New Zealand, where species naturally high in tannin occur. Tannin must undergo chemical manipulation through the addition of resorcinol-, phenol- or ureaformaldehyde compounds to promote cross-linking before it develops sufficient adhesive properties; it is not nearly as raw as the veneer for plywood, but nevertheless it leads us back to the trees.

AlLisON I. FulTZ

For Further Reading: A. Pizzi, ed., Wood Adhesives: Chemistry and Technology, Vol. 1 (Marcel Dekker, New York, 1983); T.C. Jester, "Woods's Modern Miracle," Building Renovation, Fall 1995; A. J. Rhude, "Structural Glued Laminated Timber: History of Its Origins and Development," unpublished thesis, University of Minnesota, 1995. 